Planning practice and academic research: Views from the parallel worlds

Robin Goodman (corresponding author)

School of Global Urban and Social Studies

RMIT University

PO Box 2476, Melbourne 3001

Australia

+61399252527

robin.goodman@rmit.edu.au

Robert Freestone

University of New South Wales

Sydney, 2052

Australia

+61293854836

r.freestone@unsw.edu.au

Paul Burton ${ }^{1}$

Cities Research Centre, Gold Coast campus,

Griffith University,

QLD 4222,

Australia

+610755527047

p.burton@griffith.edu.au

Key words: Planning practice, theory, academic research, Australia and New Zealand

\footnotetext{
${ }^{1}$ We acknowledge the vital inputs into setting up the questionnaire and data analysis from Raven Cretney (RMIT), Elizabeth Taylor (RMIT) and Heather Shearer (Griffith).
} 


\begin{abstract}
There are many different types of planners, but a common distinction can be made between those working in academic settings and those in public or private professional practice. Despite their different roles, academic and professional planners share many common goals. Both are typically concerned with the future of cities and regions, with engagement with goals of sustainability, equity and prosperity. Many academics hope to contribute knowledge and influence professional planners and policy makers to improve current practice. Similarly, many practitioners wish to draw upon current research which seeks identify and promulgate best practice thinking in their particular area.

Yet while this symbiotic relationship may appear clear in principle, in practice the two groups often find it difficult to connect and barriers to effective communication remain (Bounds and Phibbs 2014; Hurley et al 2016; Taylor and Hurley 2016). This paper reports on a survey conducted in 2015-16 of both academic and practitioner planners in Australia and New Zealand, which asked respondents to consider the state of the theory/practice divide. The survey of more than 250 respondents provides a rich compendium of views and insights into this vexed issue. The results will resonate with planners internationally on this widespread problematic issue.
\end{abstract}




\section{Introduction}

There are many different types of planners, but a commonplace distinction is made between planners working in academic settings and those working in professional practice, in either the public or the private sector. Most academic planners are engaged mainly in both teaching and research, while most professional practice planners contribute only occasionally to teaching or to long-term research projects. Nevertheless, academic and professional planners share many common goals. Both are typically concerned with the future of cities and regions, with varying degrees of engagement with broader goals of sustainability, equity and prosperity. Many academics hope to build and contribute knowledge which will improve the professional practice of planning, an aspiration which depends upon their ability to influence professional planners and policy makers. Similarly, many practitioners wish to draw upon current research on planning theory and research which seeks identify and promulgate best practice thinking in their particular area, often available only through academic forums. Yet while this symbiotic relationship may appear clear in principle, in practice the two groups often find it difficult to connect and barriers to effective communication remain (Bounds and Phibbs 2014; Hurley et al 2016; Taylor and Hurley 2016).

Securing a better relationship between the academic and professional planning practice is a perennial concern, (Bunker 2015) including for professional associations (refs) while $\mathrm{Wu}$ and Brooks (2012, p.133) have suggested "the two sets of activities sometimes appear to reflect two entirely different worlds, each with its own distinctive culture".

Planning, as an academic discipline, remains mainly applied although the last forty years has seen a growing body of work produced by planning theorists whose principal concerns are with the advancement of knowledge rather than the direct and immediate application of their work in professional practice settings. A major purpose of much academic planning research is therefore connected to informing and seeking to shape practice, whilst at the same time being driven by a commitment to knowledge creation and not wanting to be tied too closely to the instrumental concerns of professional practitioners (Durning 2004; Taylor and Hurley 2015). These differing goals need not of course be in conflict, and there are good examples of how planning research can be both scholarly and have high impact beyond the academy, as Flyvbjerg (2012) has demonstrated in his analysis of the use of media to support greater. However, much academic planning research is neither so readily applied or so successful disseminated, and there are current concerns (who: ref) that a gulf exists between these worlds and may be widening.

\section{Evidence of a growing gulf}

The apparent gulf between the worlds of academic and professional planning practice is often couched as a divide between theory and practice. While this has some utility 
as a shorthand device, it can also obscure some important distinctions (for example, between different value positions in planning) and overemphasize others (such as distinctions between the natural and built environment). We use the term below mindful of these caveats.

A recent study of European planners found that the gulf between theory and practice is growing larger and more intransigent (Kunzmann \& Koll-Schretzenmayr, 2015a; 2015b). This study surveyed planners from a across Europe and received responses from 34 planners across 18 countries and asked six broad, open-ended questions covering a range of topics, including: 'Is the gap between theory and practice in planning growing in your country?' and 'What role does English planning literature play in this discourse?'. The study concluded that the gulf was growing and suggested two main reasons for it: firstly, that there were now fewer practitioners involved in teaching at universities than in the past, a consequence probably of changing academic appointment criteria in many countries, and secondly, that academics publish increasingly in specialised journals in English, which may not be widely accessible to practitioners as they are protected by publishers' paywalls, but are not seen by them as addressing concern or relevance to their practice. Half of the respondents indicated that the literature found in academic planning journals "had no thematic relevance for the respective national planning practice" and that "the international world of theoretical planning discourse is mostly irrelevant to the planning reality of their own countries" (Kunzmann \& Koll-Schretzenmayr, 2015a p.88). A subsequent study of planning in a number of Asian countries confirmed a similarly widening gap between theory and practice driven by a variety of cultural and professional factors. The views of North American planners have also been surveyed on a number occasions (eg Perloff, 1957, Guzzetta \& Bollens, 2003, Whittemore, 2015) and similar concerns raised about the apparent divide and how it might be reduced (Dawkins, 2016).

There have also been recent Australian investigations into this issue. Taylor and Hurley (2015) conducted interviews with a sample of local government planners to examine their use of academic research. They found that practicing planners rarely read academic research outputs, despite often agreeing that it was valuable in principle and that "planning practice does not make enough use of evidence in decision-making" (2015 p. 3). Reasons for this include a range of significant barriers inhibiting easy access and comprehension. One of these barriers is the abstract and conceptual manner in which planning issues are sometimes discussed in academic forums, and the perceived disconnection with local conditions and concerns, echoing the findings of Kunzmann \& Koll-Schretzenmayr and of Taylor and Hurley who have argued, "The time and reflection required to digest and interpret the local relevance of research is part of what makes academic publications seem inaccessible" (2015, p.5). In place of academic research, the practitioners in the Taylor and Hurley study preferred to get their information from the internet via 
search engines or curated sites, blogs or other sources which to them provided current planning 'accepted wisdom'.

Another Australian study undertaken by researchers at the University of Queensland looked into the use of academic research more broadly by over 2000 staff in 21 different public sector agencies involved in policy making within the human services sector (Chereny et al 2015). This found a degree of variation in the use of academic research in policy making across organisations which was determined in part by organisational culture and the value placed on academic research (Chereny et al 2015 , p.181). For practitioners to habitually utilise research "there must also be a climate in which the use and adoption of research evidence is expected, encouraged and valued" (Chereny et al 2015, p. 183). Ease of access to research information was also important as was the existence of 'knowledge infrastructure' to productively use research once accessed. Given the day to day pressures of work in professional practice, the degree of convenience and expediency in being able to access research data and conclusions will affect how much research is actually used in practice. Finally, the study emphasised that the degree to which public servants would seek out the results of research might depend on the reputation of the researcher, "If academics are interested in ensuring their research has an influence, they need to build close relationships with public officials" (Chereny et al 2015, p. 183).

\section{Surveying Australian and New Zealand planners - methods}

To explore these issues further, and see whether the European, Asian and North American findings might hold true in an Australian and New Zealand context, we conducted our own on-line survey of planners, utilising an email network (RePlan) of Australasian planners (academics and practitioners) with approximately 350 subscribers and selective notices in professional planning newsletters produced by the Planning Institute of Australia (PIA) and the New Zealand Planning Institute (NZPI). nterested planners were directed to an online survey site which was live from early December 2015 to late March 2016. The survey, conducted using the Qualtrics platform, asked respondents to answer approximately 20 questions through a mix of closed and open responses, with some addressed separately to either academic or practitioners with the responses to the open ended questions analysed using NVivo software. The survey covered three broad areas of enquiry: the relationship and relevance of planning theory and research to planning policy and practice; the general state of planning, including current challenges and confidence in profession in meeting them; and the state of planning education. This paper reports mainly on the findings of the first area - the relationship of theory to practice. 
The relevant questions from the survey are described in Table 1.

\section{Insert Table 1 about here}

The survey attracted a total of 255 respondents although not all completed every question. The majority of respondents (69\%) identified themselves as professional practitioners while $31 \%$ identified as planning academics. The largest group of practitioners worked in the public sector, but there were also a large group working in the private sector and a smaller number of self-employed planning consultants. The gender distribution of respondents was more even with $53 \%$ male and $45 \%$ female, compared with the membership of profile of PIA (2016) which was $61 \%$ male and $39 \%$ female.

\section{Survey Findings: Importance of the relationship between research, theory and practice}

There was general agreement from our respondents that the relationship of academic research and planning theory to planning practice was important, and that the relationship between these two planning 'worlds' was also important (see Figure 1). Of 216 respondents to these questions, academics were a little stronger in their agreement, particularly regarding the importance of relations between the groups. This question received the highest proportion of 'strongly agree' responses, which came predominantly from the academics - $62 \%$ thought this, while only $32 \%$ of practitioners felt that strongly. For all three questions neither group had less than $78 \%$ either agreeing or strongly agreeing with the proposition (see Table 2).

\section{Insert Figure 1 about here}

Table 2 provides a more detailed breakdown of these responses.

\section{Insert Table 2 about here}

Academic respondents were generally very positive about the value of their relationships with professional practitioners. Some $66 \%$ of the total of 56 who answered this question agreed or strongly agreed they had good connections with the 
planning profession, while $18 \%$ were neutral and $16 \%$ disagreed or strongly disagreed. However, academics had fewer ties to the development industry with only $27 \%$ agreeing or strongly agreeing, $43 \%$ disagreeing or strongly disagreeing and $30 \%$ effectively expressing an equivocal view (see Figure 2).

\section{Insert Figure 2 about here}

\section{Usefulness of Research - academics}

The academics had a fairly optimistic view of the usefulness of their research with two thirds $(66 \%)$ agreeing or strongly agreeing that the planning research they conducted or read was helpful to planning practice. Only 5\% thought this was not the case but just under one third (29\%) were non-committal.

Just over half the academics (52\%) said they wrote for both academic and practitioner audiences. There were many open-ended answers in this category with some explaining that the particular audience depended on the circumstances. For example, one respondent described their publications as being largely in academic journals but occasionally in outlets designed to be more widely accessed, such as The Conversation (theconversation.com) in order to reach non-academics. Another replied that they wrote "..mainly at an academic audience. But I do deliberately publish a lot of grey literature, even though I know it doesn't help my career progression".

However, 20\% said that their research was primarily designed an academic audience only and published in journals accessed typically only by academics. This was explained as being driven mainly by the traditional expectations of academic excellence required by their university employers. One respondent captured this vividly, stating that they wrote for "...academic audiences for track record building. This is determined by the 'publish or perish' game rule of today's universities". Another indicated "that is what the system recognises", while a third spoke for many others in stating "that is how the metrics are measured - the better quality journals are not the practitioner ones".

Several respondents noted that they tried to incorporate some elements of practitioner relevant material, targeting primarily "an academic audience [but] with a nod to policy makers and planning practitioners". Of the respondents that wrote and designed research more specifically for policy makers and practitioners there was a strong emphasis on the importance of addressing a "wider audience" for their research, and articulating recommendations useful for policy makers. One respondent noted that their focus on policy makers and practitioners was "to the detriment of my academic career". Another described their research as "problem based - so it seeks to 
[be] rooted in practice, with a practice oriented outcome". Some said there were other audiences they were aiming at such as grassroots communities, students and international readers.

When asked to specify how they went about trying to influence policy and practice through their research, academics most commonly indicated they did so by speaking at conferences ( 21 respondents) and a smaller number through utilising the media ( 8 respondents). The role of building relationships, networks and partnerships between practitioners, academics and policy makers was also frequently mentioned (19 respondents) as a method for academics to influence policy and practice. For example, one noted the importance of embedding practitioners and policy makers in the entire research process: "I work with policy makers and government officials during my research, so they are involved from beginning to end". Another commented that they "regularly work with professionals/organisations to define project scope, methods and so forth. We work jointly to collect data and are now moving toward joint publication". Others said that they "regularly talk to practitioners about their work", "meet with key players to scope the research" and "try and build partnerships and collaboration". Others mentioned the importance of creating outputs in these relationships deriving from the research, "[we] talk to councils [and] produce reports which are widely distributed".

\section{Practitioners' views of academics and their research}

Practitioners were more equivocal about their relations with academics, being fairly evenly distributed across all answers as shown in Figure 3, while only a little over one third of them (38\%) claimed good connections with academics and for almost as many (34\%) the most common answer was to neither agree or disagree.

\section{Insert Figure 3 about here}

Just over half of the practitioners who answered this question (54\%) indicated that they did use academic research, while one quarter (24\%) said they did not. Just under half (46\%) agreed that the research was useful, while $21 \%$ indicated that it wasn't and one third (33\%) equivocated. This suggests that academic research was seen as only marginally relevant for just over half of our respondents.

The practitioners' views on what would make research more relevant to their work varied. Nearly half of the responses to this question (44 out of 91) suggested that the focus of the research itself should be different and more useful. For example, one respondent wrote that "as a practitioner I'm interested in applied research, particularly around system reform or best/better practices". A strong theme was the perceived need for more practical or applied research including calls for "less theory 
based [research] and more focused on an analysis of the impacts of the implementation of specific projects", and research that "..can be more practically focused, dealing with pertinent local issues, rather than being (predominantly) academic and abstract". Some specific types of desirable research were mentioned: regional cities and development were identified through specific issues, "greater focus on regional areas - how regulatory barriers around water planning and allocations will create more opportunities to build Northern Australia for example" and "how to improve government policy!". One respondent commented that "there is too much 'me too' research and publication by academics on topics for which they are not qualified or suited to deliver strong impact", while another suggested academics should "stop pandering to the development industry".

About one quarter of respondents to this question described the accessibility of research as an important issue of concern. The accessibility of research was both in terms of the nature of publications as well as restrictions around access to journals through pay walls and subscriptions. Respondents specifically discussed the need for research to be "prepared for professional journals so that the profession is aware of the existence of the research". The language used in articles was mentioned; complaints were that the research needs to be "readily understood" and "much of it needs to be more accessible in terms of its language". Many commented on the difficulties of accessing academic research, "as most is found in journals that need to be paid for". It would be preferable "if they were somehow better accessible without subscriptions to academic sites or related fees", while another suggested "they could set up regular academic research updates - open (and free of charge) - to keep practitioners up to date. This would be beneficial to both sides".

About $20 \%$ of practitioners responding to this question indicated that greater collaboration with academics was needed. Some suggested a need for "willingness by academics to present to industry on new or emerging research topics" and that research should "be done in partnership with practitioners, academics should guide the process...sign the ethics form and do the paper work. Let the practitioners table the research. One respondent noted that they found "some academics not always willing to share knowledge or helpful in guiding early academics" and another noted that "there is probably a function that could be described as 'outreach' that is missing".

\section{Improving relations between the 'two worlds'}

There were 160 (54 academic and 106 practitioner) respondents to the question asking for ideas on how better relationships between academic and practitioners might be cemented. By far the most common theme for answers in total and across both sets of respondents suggested that there needed to be more collaboration and engagement between the groups. Participants described the need for "more academic-practitioner opportunities for collaboration", "better links between academia and continuing professional education of planners", "joint projects", 
"greater transparency and communication, leading to greater collaboration" and "project opportunities". Some suggested practical solutions towards this goal such as: "closer engagement to understand the priorities for current practice", "encouraging governments to allow staff to research events" and suggestions that the Planning Institute of Australia "could invite more involvement with researchers". One participant postulated that achieving these "stronger relationships between academics and practitioners would need more 'practical' academics and 'open minded' practitioners".

Greater access to academic research was also commonly brought up as a way of promoting better closer relations between the two groups, suggested by 27 respondents ( 9 academics and 18 practitioners). A number of respondents suggested that easier access to planning research would be helpful while some mentioned specific means such as seminars or conferences, non-academic forums, newsletters and updates as well as forms of accessing the research that did not rely on having to read a lot of academic work. One respondent wrote that "the documents need to be more succinct and to the point as planning practitioners do not have time to read through pages and pages of drivel that academics deem necessary.." Another suggested that "academics need to promote their work to practitioners - not just talk to themselves or occasionally to the media". Another respondent called more generally for "better understanding by the profession into the academic publishing requirements and how research will be published and structured".

Another common theme, and the second most popular response from practitioners (with 22 responses), was that academic research needed to have a more practical focus. Suggestions here included "making sure the realities of planning is in the practice", "getting academics out of universities and spending time in operating companies", "academics and researchers being placed in Local Governments on research projects" and "more practical understanding of what practitioners do". Some of these ideas echo the career reflections of senior academics like Ann Markusen (2015) who endorses career trajectories mixing scholarship with practice (and activism). In our survey, the focus on encouraging academics to explore what practitioners see as more grounded realities was clear, such as "making sure that the academics are focusing on real, tangible issues rather than creating a utopia".

Several practitioners suggested there should be a greater involvement of practicing planners in planning education at universities, resonating with the findings of the Kunzmann-Koll survey (2015). Suggestions included "integrating practitioners into planning education" and "utilising practitioners more in teaching and academics being involved in consulting research". Practitioners suggested guest lecturing positions would be useful, though this mode of experiential learning is already widely adopted (Slade et al 2015).

\section{Discussion and Conclusion}


Our survey results indicated both similarities and some differences with Kunzmann highly rated academic journals not usually read by practitioners was an issue in common, with the formal and sometimes convoluted language used in these forums seen by practitioners as problematic. For many Europeans, writing in English, when not the language of their practice, created a barrier, but for the Australian and New Zealand survey respondents it was academic jargon and obscure language which presented a greater barrier to some practitioners.

The European survey found the growing divide between theory and practice was exacerbated by the fact that few practitioners teach in planning programs and have regular contact with planning students (Kunzmann and Koll-Schretzenmayr 2015a, p. 88). This was generally echoed in our study in answer to questions around the adequacy of planning education, arguably weighted toward the dominant practitioner voice among respondents and perhaps some wanting to get involved more closely with tertiary education. However many respondents mentioned the need for more practical training within planning education - the need for students to get professional experience while studying as a way of bridging the theory/practice gap. This is despite most PIA accredited planning programs in Australia having some form of practicum or work integrated learning component.

Overall, it would seem that our survey provides more reason for optimism than its European counterpart. While the gap between the two worlds is acknowledged it is not seen in such a pessimistic light. The academic respondents in particular felt confident that research was important and useful to practice with two thirds expressing this as well as believing that they had good relationships with practitioners. The gap is clearly felt more by practitioners than academics, with less than half of this group finding academic research actually useful to practice. While the sample size for this survey was large enough for the findings to be significant, it should be borne in mind that recruitment was promoted through an online emailing list of interested planners. It could be argued that practitioners who subscribe to such a list are perhaps more engaged and more interested in gaining access to outside sources of information than might otherwise be the case. A sample of respondent practitioners selected at random might perhaps have shown less interest in research, though this is speculation on our part.

That the academics responding to our survey generally appear to believe their work is more important and useful than the group of practitioners could be characterised as optimistic, or more harshly as simply unaware or insensitive to the realities of working life in the planning profession. Nevertheless there is clear evidence of goodwill all round, and many good and constructive suggestions around improving relations surfaced. Institutional challenges to bridging the research-practice divide still persist and these are, worryingly, often felt more acutely by early career research academics (Hurley and Taylor 2016). 
Our survey respondents focussed strongly on mechanisms that would encourage greater collaboration. This was through the choice of research topics, as well as developing vehicles for working cooperatively and through wider research dissemination. Interestingly, utilising the media as suggested by Flyvbjerg (2012) was not always seen as a positive way of engaging practitioners, but as a form of self-promotion for academics giving gratuitous advice from afar. Finding the best means to effectively convey research findings to practitioners is clearly a pressing need. Journal pay walls remain a major barrier to practitioners outside universities or large institutions such as government departments which might subscribe. Some of the suggestions for better communication identified by our respondents fit well with those of Bunker (2015). His ideas include the increasing use of commentary or practice review sections in journals, where different academic standards might be applied; short summaries of research results released electronically in accessible form for practitioners; and the establishment of a research-practice exchange website similar to that hosted by the Royal Town Planning Institute in Britain.

It is an understatement to conclude that the relationship between planning researchers and practitioners is neither easy nor straightforward (Hurley et al 2016, 447) rather than easy and straightforward, and bridging that gap is a cultural, institutional and workplace challenge. Communication will be central to bridging the gap in the future and new forums for interaction between practitioner and academic planners need to be fostered and encouraged. Professional associations like PIA, NZPI and the RTPI offer such opportunities and these could be further enhanced through deliberative efforts on their part to further engage, as was suggested by some respondents. The final word can go to one of our respondents who wrote "I think the basic underlying issue is the need for a means for better communication (allowing constructive debate) between everyone involved in planning". Finding the means for this improved communication is perhaps the challenge, but the goodwill expressed within this survey to make it happen must surely be encouraging.

Three final points can be made in conclusion. First, surveys such as ours are able to paint a broad picture of the current state of planning and to the nature of any gap between the worlds of academic and professional planning practice. They are not necessarily the best way of understanding in detail why planners hold the views they do. It is possible that more intensive explorations with individuals or groups of planners might reveal more nuanced positions that combine to a more complex overall picture. Second, recent moves by the Australian government to introduce new criteria into their assessment of the research performance of Australian universities might help bridge the gap with professional practice. Engagement and impact beyond the academy have been introduced into the regulatory and assessment regime and it is highly likely that academics, including planning academics, will pay more attention to constructing new narratives of engagement and impact around their research, even if some do so reluctantly. Third, it does not necessarily follow that greater engagement between academics and practitioners will always be a precursor 
to greater research impact on planning practice. The relationship between research and policy and between policy and practice in any field is rarely straightforward (Burton, 2006), but this should not prevent academics from conducting research of the highest possible standards, seeking wherever possible to be guided by the imperatives of practitioners and to communicate the results of their research in a variety of forums and formats, including ones accessible to busy practitioners. If practitioners are similarly committed to reading current planning research and considering how it might improve their practice, then the two worlds of planning might come closer together to the benefit of society as a whole. 


\section{References}

Bounds, M. and Phibbs, P. (2014) 'Putting Practice into Theory: Reconciling academic discourse with experience', Planning, Politics and People: Proceedings of the Australia \& New Zealand Association of Planning Schools Conference (ed) M. Imran, J. Ross and I. Luxmoore, Massey University, Palmerston North, New Zealand.

Bunker, R. (2015) Linking Urban Research with Planning Practice, Urban Policy and Research, 33(3), pp. 362-369, DOI: 10.1080/08111146.2015.1034854

Burton, P. (2006) Modernising the policy process: making policy research more significant, Policy Studies, vol 27, no 3, 173-195

Cherney, A., Head, B., Povey, J., Ferguson, M. \& Boreham, P. (2015) 'Use of academic social research by public officials: exploring preferences and constraints that impact on research use', Evidence \& Policy, 11(2), pp. 169-88. http://dx.doi.org/10.1332/174426514X14138926450067

Dawkins, C. (2016) Preparing Planners: The Role of graduate Planning Education, Journal of Planning Practice and Research, vol 36, no 4, 414-426

Durning, B. (2004) Planning academics and planning practitioners: two tribes or a community of practice? Planning Practice and Research, 19(4), pp. 435-446, $10.1080 / 0269745052000343262$

Flyvbjerg, B. (2012) Why Mass Media Matter to Planning Research: The Case of Megaprojects, Journal of Planning Education and Research, 32(2), pp. 169-181, DOI: $10.1177 / 0739456 X 12441950$

Guzzetta. J. \& Bollens, S. (2003) Urban Planners' Skills and Competencies: Are We Different from Other Professions? Does Context Matter? Do We Evolve? Journal of Planning Education and Research 23:96-106

Hurley, J. \& Taylor, E.J. (2016) Australian early career planning researchers and the barriers to research-practice exchange, Australian Planner, 53(1), pp. 5-14. DOI: 10.1080/07293682.2015.1135813

Hurley, J. Lamker C.W., Taylor, E.J. Stead, D., Hellmich, L.L, Rowe, H., Beeck, S., Phibbs P. \& Forsyth, A. (2016) Exchange between researchers and practitioners in urban planning: achievable objective or a bridge too far?/The use of academic research in planning practice: who, what, where, when and how?/Bridging research and practice through collaboration: lessons from a joint working group/Getting the relationship between researchers and practitioners working/ Art and urban planning: stimulating researcher, practitioner and community engagement/ Collaboration between researchers and practitioners: Political and bureaucratic issues/ Investigating 
Research/Conclusion: Breaking down barriers through international practice?,

Kunzmann, K.R. \& Koll-Schretzenmayr, M. (2015a) The State of the Art of Planning in Europe. Introduction: Planning and Planning Education in 2015, disP - The Planning Review, 51(1), pp. 16-17.

Kunzmann, K.R. \& Koll-Schretzenmayr, M. (2015b) A Planning Journey Across Europe in the Year 2015, disP - The Planning Review, 51(1), pp. 86-90, DOI: 10.1080/02513625.2015.1038081

Kunzmann, K.R. (2015) The State of the Art of Planning and Planning Education in Asia, disP - The Planning Review, 51(4), pp. 42-51, DOI:

10.1080/02513625.2015.1134961

Markusen, A.R. (2015) How Real-World Work, Advocacy, and Political Economy Strengthen Planning Research and Practice, Journal of the American Planning Association, 81(2), pp. 143-152, DOI: 10.1080/01944363.2015.1040053

Perloff, H. (1957) Education for Planning: City, State and Regional.Baltimore, MD: Johns Hopkins University Press.

Slade, C., Harwood, A., Baldwin, C., \& Rosier, J. (2015) Baseline survey of current experiential learning practice in Australian and New Zealand planning schools, Australian Planner, 52(2), pp. 103-113. DOI: doi:10.1080/07293682.2014.926280

Taylor, E.J. \& Hurley, J (2015) Not a Lot of People Read the Stuff: Australian Urban Research in Planning Practice, Urban Policy and Research, 34 ( ), pp. 116-131. DOI:10.1080/08111146.2014.994741

Whittemore, A. (2015) Practitioners Theorize, Too: Reaffirming Planning Theory in a Survey of Practitioners' Theories, Journal of Planning Practice and Research, vol 35 , no1, 76-85

Wu, W. and Brooks, M (2012) The Engagement of Planning Scholarship with Practice: Brief Introduction to Symposium, Journal of Planning Education and Research 32(2), pp. 133-134, DOI: 10.1177/0739456X12443506 
Table 1: Survey questions on relations between planning theory and practice

All respondents were asked:

How important do you consider the following relationships to be:

- Academic research to planning practice?

- Planning theory to planning practice?

- Working relationships between academics and planning practitioners?

How might these three relationships be better promoted?

Academics were asked:

As an academic, to what extent do you think that:

- You have good connections with the planning profession?

- You have good connections with the development industry?

- The planning research you conduct, read or see published is helpful to planning practice?

When designing and publishing your research is it aimed primarily at an academic audience or a wider audience of policy makers and practitioners?

If you seek to influence planning policy and practice with your research, what steps beyond publication - do you take to do this and how effective do you think these have been?

Practitioners were asked:

As a planning professional, to what extent do you think:

- You have good connections with the planning academics?

- You are a consumer of academic planning research?

- Academic research is relevant to your needs?

How might academic research be made more relevant to you? 
Figure 1 Responses to importance of relationships, all respondents

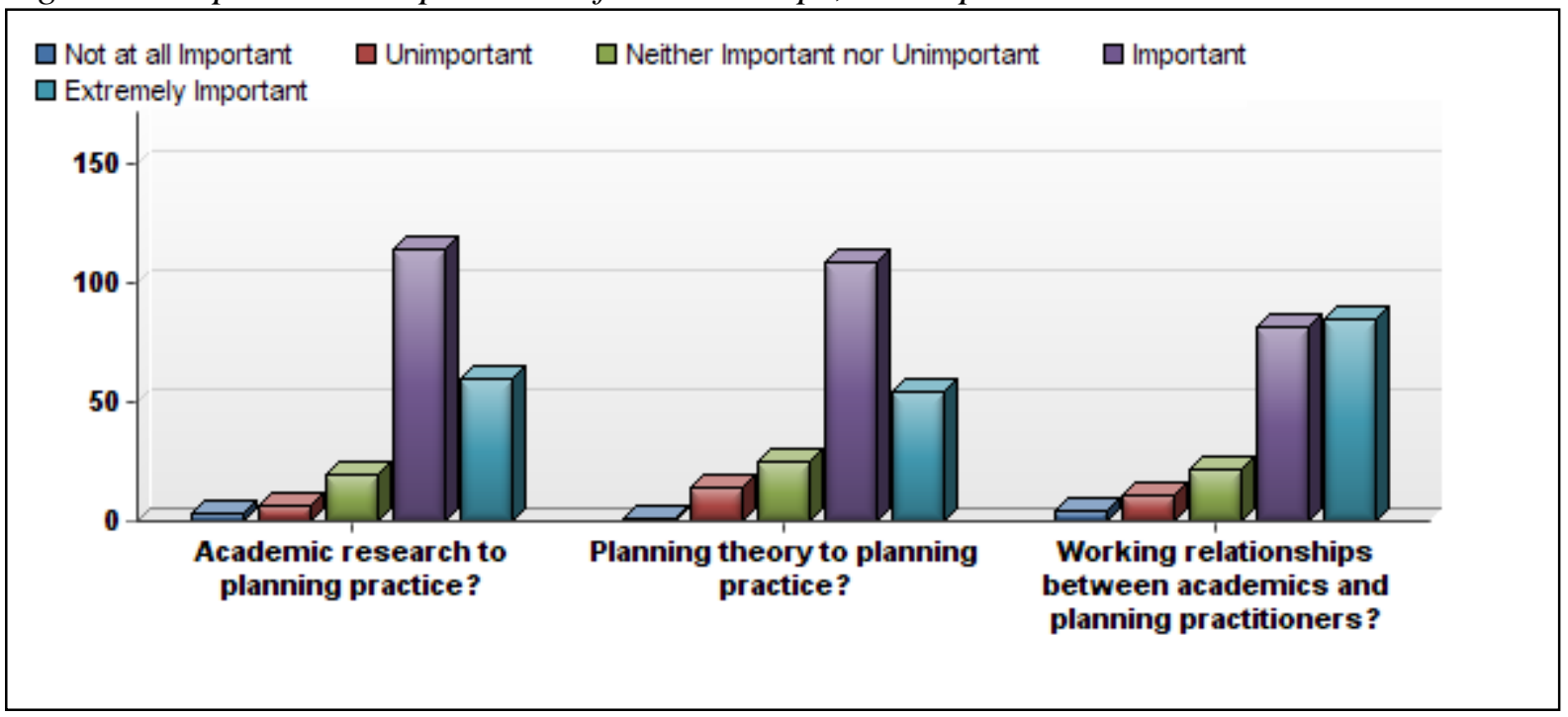


Table 2: Importance of relationships by occupational group

\begin{tabular}{|c|c|c|c|}
\hline & $\begin{array}{l}\text { Important and } \\
\text { extremely important }\end{array}$ & $\begin{array}{l}\text { Unimportant or } \\
\text { extremely } \\
\text { unimportant }\end{array}$ & $\begin{array}{l}\text { Neither important or } \\
\text { unimportant }\end{array}$ \\
\hline \multicolumn{4}{|c|}{ On the question of the importance of academic research to practice: } \\
\hline Academics & $92 \%$ & $4 \%$ & $3 \%$ \\
\hline Practitioners & $82 \%$ & $6 \%$ & $12 \%$ \\
\hline \multicolumn{4}{|c|}{ The importance of planning theory to practice: } \\
\hline Academics & $81 \%$ & $9 \%$ & $10 \%$ \\
\hline Practitioners & $78 \%$ & $9 \%$ & $13 \%$ \\
\hline \multicolumn{4}{|c|}{ The working relationship between the groups: } \\
\hline Academics & $90 \%$ & $6 \%$ & $4 \%$ \\
\hline Practitioners & $78 \%$ & $9 \%$ & $13 \%$ \\
\hline
\end{tabular}


Figure 2: Academics' connections

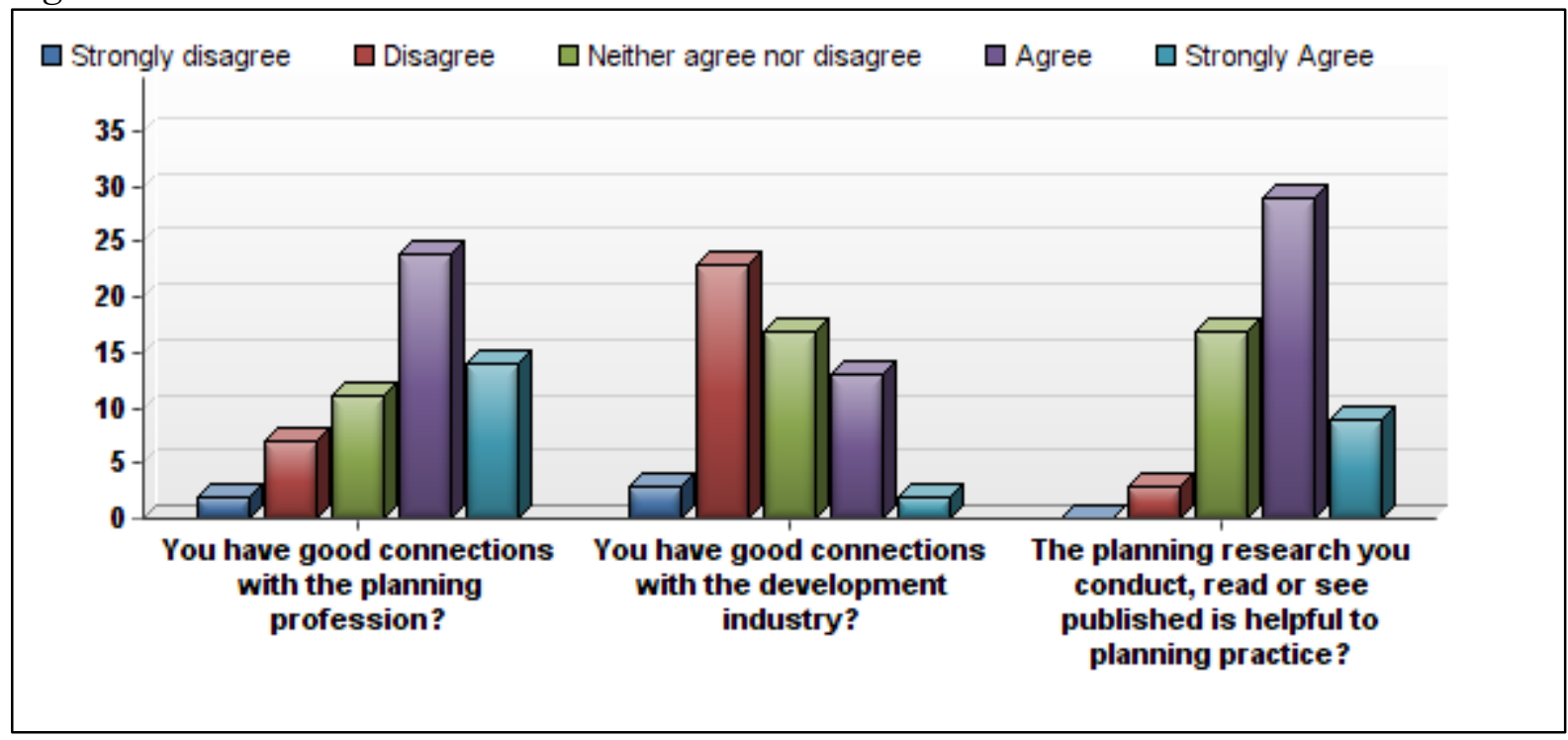


Figure 3: Practitioners connections

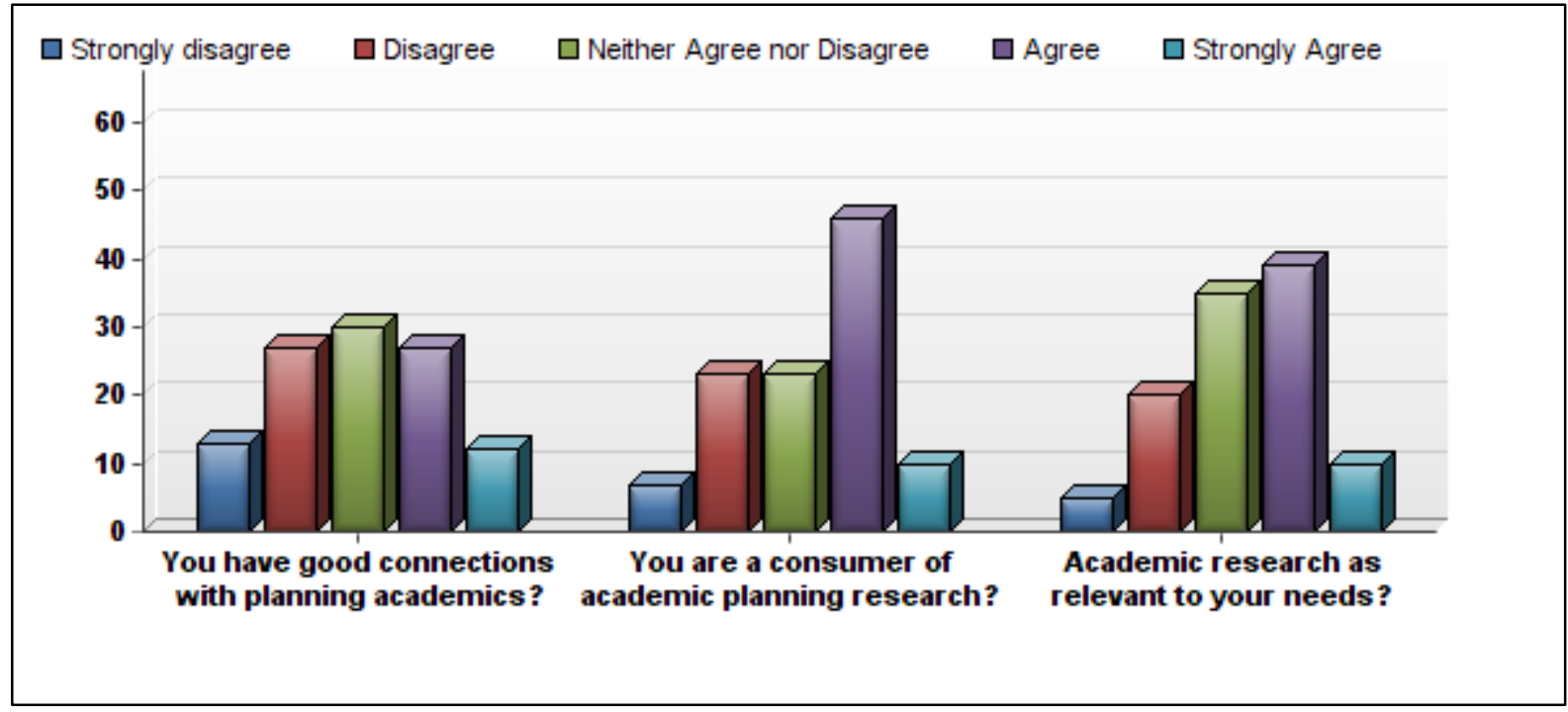


Planning practice and academic research: Views from the parallel worlds

Key words: Planning practice, theory, academic research, Australia and New

Zealand

\author{
Zealand
}

\title{
Planning practice and academic research: Views from the parallel worlds
}

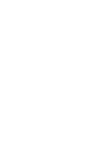

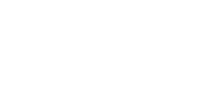




\begin{abstract}
There are many different types of planners, but a common distinction can be made between those working in academic settings and those in public or private professional practice. Despite their different roles, academic and professional planners share many common goals. Both are typically concerned with the future of cities and regions, with engagement with goals of sustainability, equity and prosperity. Many academics hope to contribute knowledge and influence professional planners and policy makers to improve current practice. Similarly, many practitioners wish to draw upon current research which seeks identify and promulgate best practice thinking in their particular area.

Yet while this symbiotic relationship may appear clear in principle, in practice the two groups often find it difficult to connect and barriers to effective communication remain (Bounds and Phibbs 2014; Hurley et al 2016; Taylor and Hurley 2016). This paper reports on a survey conducted in 2015-16 of both academic and practitioner planners in Australia and New Zealand, which asked respondents to consider the state of the theory/practice divide. The survey of more than 250 respondents provides a rich compendium of views and insights into this vexed issue. The results will resonate with planners internationally on this widespread problematic issue.
\end{abstract}




\section{Introduction}

There are many different types of planners, but a commonplace distinction is made between planners working in academic settings and those working in professional practice, in either the public or the private sector. Most academic planners are engaged mainly in both teaching and research, while most professional practice planners contribute only occasionally to teaching or to long-term research projects. Nevertheless, academic and professional planners share many common goals. Both are typically concerned with the future of cities and regions, with varying degrees of engagement with broader goals of sustainability, equity and prosperity. Many academics hope to build and contribute knowledge which will improve the professional practice of planning, an aspiration which depends upon their ability to influence professional planners and policy makers. Similarly, many practitioners wish to draw upon current research on planning theory and research which seeks identify and promulgate best practice thinking in their particular area, often available only through academic forums. Yet while this symbiotic relationship may appear clear in principle, in practice the two groups often find it difficult to connect and barriers to effective communication remain (Bounds and Phibbs 2014; Hurley et al 2016; Taylor and Hurley 2016).

Securing a better relationship between the academic and professional planning practice is a perennial concern, (Bunker 2015) including for professional associations (refs) while Wu and Brooks (2012, p.133) have suggested "the two sets of activities sometimes appear to reflect two entirely different worlds, each with its own distinctive culture".

Planning, as an academic discipline, remains mainly applied although the last forty years has seen a growing body of work produced by planning theorists whose principal concerns are with the advancement of knowledge rather than the direct and immediate application of their work in professional practice settings. A major purpose of much academic planning research is therefore connected to informing and seeking to shape practice, whilst at the same time being driven by a commitment to knowledge creation and not wanting to be tied too closely to the instrumental concerns of professional practitioners (Durning 2004; Taylor and Hurley 2015). These differing goals need not of course be in conflict, and there are good examples of how planning research can be both scholarly and have high impact beyond the academy, as Flyvbjerg (2012) has demonstrated in his analysis of the use of media to support greater. However, much academic planning research is neither so readily applied or so successful disseminated, and there are current concerns (who: ref) that a gulf exists between these worlds and may be widening.

\section{Evidence of a growing gulf}

The apparent gulf between the worlds of academic and professional planning practice is often couched as a divide between theory and practice. While this has some utility 
as a shorthand device, it can also obscure some important distinctions (for example, between different value positions in planning) and overemphasize others (such as distinctions between the natural and built environment). We use the term below mindful of these caveats.

A recent study of European planners found that the gulf between theory and practice is growing larger and more intransigent (Kunzmann \& Koll-Schretzenmayr, 2015a; 2015b). This study surveyed planners from a across Europe and received responses from 34 planners across 18 countries and asked six broad, open-ended questions covering a range of topics, including: 'Is the gap between theory and practice in planning growing in your country?' and 'What role does English planning literature play in this discourse?'. The study concluded that the gulf was growing and suggested two main reasons for it: firstly, that there were now fewer practitioners involved in teaching at universities than in the past, a consequence probably of changing academic appointment criteria in many countries, and secondly, that academics publish increasingly in specialised journals in English, which may not be widely accessible to practitioners as they are protected by publishers' paywalls, but are not seen by them as addressing concern or relevance to their practice. Half of the respondents indicated that the literature found in academic planning journals "had no thematic relevance for the respective national planning practice" and that "the international world of theoretical planning discourse is mostly irrelevant to the planning reality of their own countries" (Kunzmann \& Koll-Schretzenmayr, 2015a p.88). A subsequent study of planning in a number of Asian countries confirmed a similarly widening gap between theory and practice driven by a variety of cultural and professional factors. The views of North American planners have also been surveyed on a number occasions (eg Perloff, 1957, Guzzetta \& Bollens, 2003, Whittemore, 2015) and similar concerns raised about the apparent divide and how it might be reduced (Dawkins, 2016).

There have also been recent Australian investigations into this issue. Taylor and Hurley (2015) conducted interviews with a sample of local government planners to examine their use of academic research. They found that practicing planners rarely read academic research outputs, despite often agreeing that it was valuable in principle and that "planning practice does not make enough use of evidence in decision-making" (2015 p. 3). Reasons for this include a range of significant barriers inhibiting easy access and comprehension. One of these barriers is the abstract and conceptual manner in which planning issues are sometimes discussed in academic forums, and the perceived disconnection with local conditions and concerns, echoing the findings of Kunzmann \& Koll-Schretzenmayr and of Taylor and Hurley who have argued, "The time and reflection required to digest and interpret the local relevance of research is part of what makes academic publications seem inaccessible" (2015, p.5). In place of academic research, the practitioners in the Taylor and Hurley study preferred to get their information from the internet via 
search engines or curated sites, blogs or other sources which to them provided current planning 'accepted wisdom'.

Another Australian study undertaken by researchers at the University of Queensland looked into the use of academic research more broadly by over 2000 staff in 21 different public sector agencies involved in policy making within the human services sector (Chereny et al 2015). This found a degree of variation in the use of academic research in policy making across organisations which was determined in part by organisational culture and the value placed on academic research (Chereny et al 2015, p.181). For practitioners to habitually utilise research "there must also be a climate in which the use and adoption of research evidence is expected, encouraged and valued" (Chereny et al 2015, p. 183). Ease of access to research information was also important as was the existence of 'knowledge infrastructure' to productively use research once accessed. Given the day to day pressures of work in professional practice, the degree of convenience and expediency in being able to access research data and conclusions will affect how much research is actually used in practice. Finally, the study emphasised that the degree to which public servants would seek out the results of research might depend on the reputation of the researcher, "If academics are interested in ensuring their research has an influence, they need to build close relationships with public officials" (Chereny et al 2015, p. 183).

\section{Surveying Australian and New Zealand planners - methods}

To explore these issues further, and see whether the European, Asian and North American findings might hold true in an Australian and New Zealand context, we conducted our own on-line survey of planners, utilising an email network (RePlan) of Australasian planners (academics and practitioners) with approximately 350 subscribers and selective notices in professional planning newsletters produced by the Planning Institute of Australia (PIA) and the New Zealand Planning Institute (NZPI). nterested planners were directed to an online survey site which was live from early December 2015 to late March 2016. The survey, conducted using the Qualtrics platform, asked respondents to answer approximately 20 questions through a mix of closed and open responses, with some addressed separately to either academic or practitioners with the responses to the open ended questions analysed using NVivo software. The survey covered three broad areas of enquiry: the relationship and relevance of planning theory and research to planning policy and practice; the general state of planning, including current challenges and confidence in profession in meeting them; and the state of planning education. This paper reports mainly on the findings of the first area - the relationship of theory to practice. 
The relevant questions from the survey are described in Table 1.

\section{Insert Table 1 about here}

The survey attracted a total of 255 respondents although not all completed every question. The majority of respondents (69\%) identified themselves as professional practitioners while $31 \%$ identified as planning academics. The largest group of practitioners worked in the public sector, but there were also a large group working in the private sector and a smaller number of self-employed planning consultants. The gender distribution of respondents was more even with 53\% male and $45 \%$ female, compared with the membership of profile of PIA (2016) which was $61 \%$ male and $39 \%$ female.

\section{Survey Findings: Importance of the relationship between research, theory and practice}

There was general agreement from our respondents that the relationship of academic research and planning theory to planning practice was important, and that the relationship between these two planning 'worlds' was also important (see Figure 1). Of 216 respondents to these questions, academics were a little stronger in their agreement, particularly regarding the importance of relations between the groups. This question received the highest proportion of 'strongly agree' responses, which came predominantly from the academics - $62 \%$ thought this, while only $32 \%$ of practitioners felt that strongly. For all three questions neither group had less than $78 \%$ either agreeing or strongly agreeing with the proposition (see Table 2).

\section{Insert Figure 1 about here}

Table 2 provides a more detailed breakdown of these responses.

\section{Insert Table 2 about here}

Academic respondents were generally very positive about the value of their relationships with professional practitioners. Some $66 \%$ of the total of 56 who answered this question agreed or strongly agreed they had good connections with the 
planning profession, while $18 \%$ were neutral and $16 \%$ disagreed or strongly disagreed. However, academics had fewer ties to the development industry with only $27 \%$ agreeing or strongly agreeing, $43 \%$ disagreeing or strongly disagreeing and $30 \%$ effectively expressing an equivocal view (see Figure 2).

\section{Insert Figure 2 about here}

\section{Usefulness of Research - academics}

The academics had a fairly optimistic view of the usefulness of their research with two thirds $(66 \%)$ agreeing or strongly agreeing that the planning research they conducted or read was helpful to planning practice. Only 5\% thought this was not the case but just under one third (29\%) were non-committal.

Just over half the academics (52\%) said they wrote for both academic and practitioner audiences. There were many open-ended answers in this category with some explaining that the particular audience depended on the circumstances. For example, one respondent described their publications as being largely in academic journals but occasionally in outlets designed to be more widely accessed, such as The Conversation (theconversation.com) in order to reach non-academics. Another replied that they wrote "..mainly at an academic audience. But I do deliberately publish a lot of grey literature, even though I know it doesn't help my career progression".

However, 20\% said that their research was primarily designed an academic audience only and published in journals accessed typically only by academics. This was explained as being driven mainly by the traditional expectations of academic excellence required by their university employers. One respondent captured this vividly, stating that they wrote for "..academic audiences for track record building. This is determined by the 'publish or perish' game rule of today's universities". Another indicated "that is what the system recognises", while a third spoke for many others in stating "that is how the metrics are measured - the better quality journals are not the practitioner ones".

Several respondents noted that they tried to incorporate some elements of practitioner relevant material, targeting primarily "an academic audience [but] with a nod to policy makers and planning practitioners". Of the respondents that wrote and designed research more specifically for policy makers and practitioners there was a strong emphasis on the importance of addressing a "wider audience" for their research, and articulating recommendations useful for policy makers. One respondent noted that their focus on policy makers and practitioners was "to the detriment of my academic career". Another described their research as "problem based - so it seeks to 
[be] rooted in practice, with a practice oriented outcome". Some said there were other audiences they were aiming at such as grassroots communities, students and international readers.

When asked to specify how they went about trying to influence policy and practice through their research, academics most commonly indicated they did so by speaking at conferences ( 21 respondents) and a smaller number through utilising the media ( 8 respondents). The role of building relationships, networks and partnerships between practitioners, academics and policy makers was also frequently mentioned (19 respondents) as a method for academics to influence policy and practice. For example, one noted the importance of embedding practitioners and policy makers in the entire research process: "I work with policy makers and government officials during my research, so they are involved from beginning to end". Another commented that they "regularly work with professionals/organisations to define project scope, methods and so forth. We work jointly to collect data and are now moving toward joint publication". Others said that they "regularly talk to practitioners about their work", "meet with key players to scope the research" and "try and build partnerships and collaboration". Others mentioned the importance of creating outputs in these relationships deriving from the research, "[we] talk to councils [and] produce reports which are widely distributed".

\section{Practitioners' views of academics and their research}

Practitioners were more equivocal about their relations with academics, being fairly evenly distributed across all answers as shown in Figure 3, while only a little over one third of them (38\%) claimed good connections with academics and for almost as many $(34 \%)$ the most common answer was to neither agree or disagree.

\section{Insert Figure 3 about here}

Just over half of the practitioners who answered this question (54\%) indicated that they did use academic research, while one quarter (24\%) said they did not. Just under half (46\%) agreed that the research was useful, while $21 \%$ indicated that it wasn't and one third (33\%) equivocated. This suggests that academic research was seen as only marginally relevant for just over half of our respondents.

The practitioners' views on what would make research more relevant to their work varied. Nearly half of the responses to this question (44 out of 91) suggested that the focus of the research itself should be different and more useful. For example, one respondent wrote that "as a practitioner I'm interested in applied research, particularly around system reform or best/better practices". A strong theme was the perceived need for more practical or applied research including calls for "less theory 
based [research] and more focused on an analysis of the impacts of the implementation of specific projects", and research that "..can be more practically focused, dealing with pertinent local issues, rather than being (predominantly) academic and abstract". Some specific types of desirable research were mentioned: regional cities and development were identified through specific issues, "greater focus on regional areas - how regulatory barriers around water planning and allocations will create more opportunities to build Northern Australia for example" and "how to improve government policy!". One respondent commented that "there is too much 'me too' research and publication by academics on topics for which they are not qualified or suited to deliver strong impact", while another suggested academics should "stop pandering to the development industry".

About one quarter of respondents to this question described the accessibility of research as an important issue of concern. The accessibility of research was both in terms of the nature of publications as well as restrictions around access to journals through pay walls and subscriptions. Respondents specifically discussed the need for research to be "prepared for professional journals so that the profession is aware of the existence of the research". The language used in articles was mentioned; complaints were that the research needs to be "readily understood" and "much of it needs to be more accessible in terms of its language". Many commented on the difficulties of accessing academic research, "as most is found in journals that need to be paid for". It would be preferable "if they were somehow better accessible without subscriptions to academic sites or related fees", while another suggested "they could set up regular academic research updates - open (and free of charge) - to keep practitioners up to date. This would be beneficial to both sides".

About $20 \%$ of practitioners responding to this question indicated that greater collaboration with academics was needed. Some suggested a need for "willingness by academics to present to industry on new or emerging research topics" and that research should "be done in partnership with practitioners, academics should guide the process...sign the ethics form and do the paper work. Let the practitioners table the research. One respondent noted that they found "some academics not always willing to share knowledge or helpful in guiding early academics" and another noted that "there is probably a function that could be described as 'outreach' that is missing".

\section{Improving relations between the 'two worlds'}

There were 160 (54 academic and 106 practitioner) respondents to the question asking for ideas on how better relationships between academic and practitioners might be cemented. By far the most common theme for answers in total and across both sets of respondents suggested that there needed to be more collaboration and engagement between the groups. Participants described the need for "more academic-practitioner opportunities for collaboration", "better links between academia and continuing professional education of planners", "joint projects", 
"greater transparency and communication, leading to greater collaboration" and "project opportunities". Some suggested practical solutions towards this goal such as: "closer engagement to understand the priorities for current practice", "encouraging governments to allow staff to research events" and suggestions that the Planning Institute of Australia "could invite more involvement with researchers". One participant postulated that achieving these "stronger relationships between academics and practitioners would need more 'practical' academics and 'open minded' practitioners".

Greater access to academic research was also commonly brought up as a way of promoting better closer relations between the two groups, suggested by 27 respondents ( 9 academics and 18 practitioners). A number of respondents suggested that easier access to planning research would be helpful while some mentioned specific means such as seminars or conferences, non-academic forums, newsletters and updates as well as forms of accessing the research that did not rely on having to read a lot of academic work. One respondent wrote that "the documents need to be more succinct and to the point as planning practitioners do not have time to read through pages and pages of drivel that academics deem necessary.." Another suggested that "academics need to promote their work to practitioners - not just talk to themselves or occasionally to the media". Another respondent called more generally for "better understanding by the profession into the academic publishing requirements and how research will be published and structured".

Another common theme, and the second most popular response from practitioners (with 22 responses), was that academic research needed to have a more practical focus. Suggestions here included "making sure the realities of planning is in the practice", "getting academics out of universities and spending time in operating companies", "academics and researchers being placed in Local Governments on research projects" and "more practical understanding of what practitioners do". Some of these ideas echo the career reflections of senior academics like Ann Markusen (2015) who endorses career trajectories mixing scholarship with practice (and activism). In our survey, the focus on encouraging academics to explore what practitioners see as more grounded realities was clear, such as "making sure that the academics are focusing on real, tangible issues rather than creating a utopia".

Several practitioners suggested there should be a greater involvement of practicing planners in planning education at universities, resonating with the findings of the Kunzmann-Koll survey (2015). Suggestions included "integrating practitioners into planning education" and "utilising practitioners more in teaching and academics being involved in consulting research". Practitioners suggested guest lecturing positions would be useful, though this mode of experiential learning is already widely adopted (Slade et al 2015).

\section{Discussion and Conclusion}


Our survey results indicated both similarities and some differences with Kunzmann and Koll-Schretzenmayr's (2015a) European survey. The pressure to publish in highly rated academic journals not usually read by practitioners was an issue in common, with the formal and sometimes convoluted language used in these forums seen by practitioners as problematic. For many Europeans, writing in English, when not the language of their practice, created a barrier, but for the Australian and New Zealand survey respondents it was academic jargon and obscure language which presented a greater barrier to some practitioners.

The European survey found the growing divide between theory and practice was exacerbated by the fact that few practitioners teach in planning programs and have regular contact with planning students (Kunzmann and Koll-Schretzenmayr 2015a, p. 88). This was generally echoed in our study in answer to questions around the adequacy of planning education, arguably weighted toward the dominant practitioner voice among respondents and perhaps some wanting to get involved more closely with tertiary education. However many respondents mentioned the need for more practical training within planning education - the need for students to get professional experience while studying as a way of bridging the theory/practice gap. This is despite most PIA accredited planning programs in Australia having some form of practicum or work integrated learning component.

Overall, it would seem that our survey provides more reason for optimism than its European counterpart. While the gap between the two worlds is acknowledged it is not seen in such a pessimistic light. The academic respondents in particular felt confident that research was important and useful to practice with two thirds expressing this as well as believing that they had good relationships with practitioners. The gap is clearly felt more by practitioners than academics, with less than half of this group finding academic research actually useful to practice. While the sample size for this survey was large enough for the findings to be significant, it should be borne in mind that recruitment was promoted through an online emailing list of interested planners. It could be argued that practitioners who subscribe to such a list are perhaps more engaged and more interested in gaining access to outside sources of information than might otherwise be the case. A sample of respondent practitioners selected at random might perhaps have shown less interest in research, though this is speculation on our part.

That the academics responding to our survey generally appear to believe their work is more important and useful than the group of practitioners could be characterised as optimistic, or more harshly as simply unaware or insensitive to the realities of working life in the planning profession. Nevertheless there is clear evidence of goodwill all round, and many good and constructive suggestions around improving relations surfaced. Institutional challenges to bridging the research-practice divide still persist and these are, worryingly, often felt more acutely by early career research academics (Hurley and Taylor 2016). 
Our survey respondents focussed strongly on mechanisms that would encourage greater collaboration. This was through the choice of research topics, as well as developing vehicles for working cooperatively and through wider research dissemination. Interestingly, utilising the media as suggested by Flyvbjerg (2012) was not always seen as a positive way of engaging practitioners, but as a form of self-promotion for academics giving gratuitous advice from afar. Finding the best means to effectively convey research findings to practitioners is clearly a pressing need. Journal pay walls remain a major barrier to practitioners outside universities or large institutions such as government departments which might subscribe. Some of the suggestions for better communication identified by our respondents fit well with those of Bunker (2015). His ideas include the increasing use of commentary or practice review sections in journals, where different academic standards might be applied; short summaries of research results released electronically in accessible form for practitioners; and the establishment of a research-practice exchange website similar to that hosted by the Royal Town Planning Institute in Britain.

It is an understatement to conclude that the relationship between planning researchers and practitioners is neither easy nor straightforward (Hurley et al 2016, 447) rather than easy and straightforward, and bridging that gap is a cultural, institutional and workplace challenge. Communication will be central to bridging the gap in the future and new forums for interaction between practitioner and academic planners need to be fostered and encouraged. Professional associations like PIA, NZPI and the RTPI offer such opportunities and these could be further enhanced through deliberative efforts on their part to further engage, as was suggested by some respondents. The final word can go to one of our respondents who wrote "I think the basic underlying issue is the need for a means for better communication (allowing constructive debate) between everyone involved in planning". Finding the means for this improved communication is perhaps the challenge, but the goodwill expressed within this survey to make it happen must surely be encouraging.

Three final points can be made in conclusion. First, surveys such as ours are able to paint a broad picture of the current state of planning and to the nature of any gap between the worlds of academic and professional planning practice. They are not necessarily the best way of understanding in detail why planners hold the views they do. It is possible that more intensive explorations with individuals or groups of planners might reveal more nuanced positions that combine to a more complex overall picture. Second, recent moves by the Australian government to introduce new criteria into their assessment of the research performance of Australian universities might help bridge the gap with professional practice. Engagement and impact beyond the academy have been introduced into the regulatory and assessment regime and it is highly likely that academics, including planning academics, will pay more attention to constructing new narratives of engagement and impact around their research, even if some do so reluctantly. Third, it does not necessarily follow that greater engagement between academics and practitioners will always be a precursor 
to greater research impact on planning practice. The relationship between research and policy and between policy and practice in any field is rarely straightforward (Burton, 2006), but this should not prevent academics from conducting research of the highest possible standards, seeking wherever possible to be guided by the imperatives of practitioners and to communicate the results of their research in a variety of forums and formats, including ones accessible to busy practitioners. If practitioners are similarly committed to reading current planning research and considering how it might improve their practice, then the two worlds of planning might come closer together to the benefit of society as a whole. 


\section{References}

Bounds, M. and Phibbs, P. (2014) 'Putting Practice into Theory: Reconciling academic discourse with experience', Planning, Politics and People: Proceedings of the Australia \& New Zealand Association of Planning Schools Conference (ed) M. Imran, J. Ross and I. Luxmoore, Massey University, Palmerston North, New Zealand.

Bunker, R. (2015) Linking Urban Research with Planning Practice, Urban Policy and Research, 33(3), pp. 362-369, DOI: 10.1080/08111146.2015.1034854

Burton, P. (2006) Modernising the policy process: making policy research more significant, Policy Studies, vol 27, no 3, 173-195

Cherney, A., Head, B., Povey, J., Ferguson, M. \& Boreham, P. (2015) 'Use of academic social research by public officials: exploring preferences and constraints that impact on research use', Evidence \& Policy, 11(2), pp. 169-88. http://dx.doi.org/10.1332/174426514X14138926450067

Dawkins, C. (2016) Preparing Planners: The Role of graduate Planning Education, Journal of Planning Practice and Research, vol 36, no 4, 414-426

Durning, B. (2004) Planning academics and planning practitioners: two tribes or a community of practice? Planning Practice and Research, 19(4), pp. 435-446, $10.1080 / 0269745052000343262$

Flyvbjerg, B. (2012) Why Mass Media Matter to Planning Research: The Case of Megaprojects, Journal of Planning Education and Research, 32(2), pp. 169-181, DOI: $10.1177 / 0739456 X 12441950$

Guzzetta. J. \& Bollens, S. (2003) Urban Planners' Skills and Competencies: Are We Different from Other Professions? Does Context Matter? Do We Evolve? Journal of Planning Education and Research 23:96-106

Hurley, J. \& Taylor, E.J. (2016) Australian early career planning researchers and the barriers to research-practice exchange, Australian Planner, 53(1), pp. 5-14. DOI: 10.1080/07293682.2015.1135813

Hurley, J. Lamker C.W., Taylor, E.J. Stead, D., Hellmich, L.L, Rowe, H., Beeck, S., Phibbs P. \& Forsyth, A. (2016) Exchange between researchers and practitioners in urban planning: achievable objective or a bridge too far?/The use of academic research in planning practice: who, what, where, when and how?/Bridging research and practice through collaboration: lessons from a joint working group/Getting the relationship between researchers and practitioners working/ Art and urban planning: stimulating researcher, practitioner and community engagement/ Collaboration between researchers and practitioners: Political and bureaucratic issues/ Investigating 
Research/Conclusion: Breaking down barriers through international practice?, Planning Theory and Practice, 17(3), pp. 447-473, DOI:

10.1080/14649357.2016.1190491

Kunzmann, K.R. \& Koll-Schretzenmayr, M. (2015a) The State of the Art of Planning in Europe. Introduction: Planning and Planning Education in 2015, disP - The Planning Review, 51(1), pp. 16-17.

Kunzmann, K.R. \& Koll-Schretzenmayr, M. (2015b) A Planning Journey Across Europe in the Year 2015, disP - The Planning Review, 51(1), pp. 86-90, DOI: $10.1080 / 02513625.2015 .1038081$

Kunzmann, K.R. (2015) The State of the Art of Planning and Planning Education in Asia, disP - The Planning Review, 51(4), pp. 42-51, DOI:

10.1080/02513625.2015.1134961

Markusen, A.R. (2015) How Real-World Work, Advocacy, and Political Economy Strengthen Planning Research and Practice, Journal of the American Planning Association, 81(2), pp. 143-152, DOI: 10.1080/01944363.2015.1040053

Perloff, H. (1957) Education for Planning: City, State and Regional.Baltimore, MD: Johns Hopkins University Press.

Slade, C., Harwood, A., Baldwin, C., \& Rosier, J. (2015) Baseline survey of current experiential learning practice in Australian and New Zealand planning schools, Australian Planner, 52(2), pp. 103-113. DOI: doi:10.1080/07293682.2014.926280

Taylor, E.J. \& Hurley, J (2015) Not a Lot of People Read the Stuff: Australian Urban Research in Planning Practice, Urban Policy and Research, 34 ( ), pp. 116-131. DOI:10.1080/08111146.2014.994741

Whittemore, A. (2015) Practitioners Theorize, Too: Reaffirming Planning Theory in a Survey of Practitioners' Theories, Journal of Planning Practice and Research, vol 35 , no1, 76-85

Wu, W. and Brooks, M (2012) The Engagement of Planning Scholarship with Practice: Brief Introduction to Symposium, Journal of Planning Education and Research 32(2), pp. 133-134, DOI: 10.1177/0739456X12443506 